\title{
CREB3L2/PPARG Fusion Protein
}

National Cancer Institute

\section{Source}

National Cancer Institute. CREB3L2IPPARG Fusion Protein. NCI Thesaurus. Code C156143.

A fusion protein encoded by the CREB3L2/PPARG fusion gene. This protein is comprised of the first 106 amino acids of the N-terminal DNA binding domain of cyclic AMPresponsive element-binding protein 3-like protein 2, including most of the transactivation domain, and the entire peroxisome proliferator-activated receptor gamma protein, including the ligand binding, DNA binding and activation domains. 